\title{
Negras(os) e brancas(os) em publicidades de jornais paranaenses
}

\author{
Paulo Vinícius Baptista da Silva* \\ Neli Gomes da Rocha*** \\ Wellington Oliveira dos Santos***
}

\begin{abstract}
Resumo
O artigo discute algumas formas específicas de hierarquização entre brancos(as) e negros(as) observadas em publicidade divulgada em jornais paranaenses. A partir de banco de dados sobre o negro em três jornais impressos de Curitiba, Gazeta do Povo, O Estado do Paraná e Tribuna do Paraná, entre os anos de 2005 e 2007, foram realizadas uma série de análises sobre aspectos específicos, entre as quais análises de amostras das peças publicitárias dos jornais. Tais peças foram submetidas a técnicas de análise de conteúdo e de análise crítica de discurso, analisando as relações entre personagens brancas(os) e negras(os). Os resultados apontam: presença e valorização de certos aspectos de personagens negros; permanência da sub-representação destes e da "branquidade normativa", o branco como norma de humanidade; vinculado a essa a expressão de uma "estética ariana”; a manutenção de velhas e novas formas de hierarquização entre brancos e negros e de estereotipia em relação a personagens negros.
\end{abstract}

Palavras chave: Relações raciais. Racismo. Publicidade. Jornais. Mídia.

\footnotetext{
* Professor doutor e Coordenador do Programa de Pós-Graduação em Educação, Faculdade de Educação, Universidade Federal do Paraná-UFPR, Curitiba-PR, Brasil. Membro do Núcleo de Estudos Afro-Brasileiros (NEAB-UFPR); coordenador do GT Educação e relações raciais da ANPED; representante da Região Sul na diretoria da Associação Brasileira de Pesquisadores(as) Negros(as) (ABPN). paulovbsilva@uol.com.br

** Socióloga, membro do Núcleo de Estudos Afro-Brasileiros (NEAB-UFPR), mestranda do Programa de Pós-Graduação em Sociologia, Faculdade de Ciências Sociais da Universidade Federal do Paraná-UFPR, Curitiba-PR, Brasil. E-mail: nelichoc@yahoo.com.br

*** Mestre em Educação, Programa de Pós-Graduação em Educação, Faculdade de Educação, Universidade Federal doParaná-UFPR, Curitiba-PR, Brasil. Psicólogo, membro do Núcleo de Estudos Afro-Brasileiros (NEAB-UFPR). E-mail: psicologowell@gmail.com
}

Intercom - RBCC 


\section{Black and white characters in newspapers advertisements of Paraná \\ Abstract}

This paper discusses some specific forms of hierarchy between whites and blacks seen in advertisements published in newspapers in Paraná (Brazil). We organized a database of black and white characters in Paraná newspapers published between 2005 and 2007: Gazeta do Povo, O Estado do Paraná e Tribuna do Paraná, and we done a series of samples on specific aspects. Advertising of distinct samples were subjected to content analysis techniques and critical analysis of discourse. This article analyzes forms of hierarchy in samples taken from the published advertisements. The results point the presence and appreciation of certain aspects of black characters; to the permanence of the "normative Whiteness," the white as standard of humanity, linked to the expression of an "Aryan aesthetic"; the maintenance of old and new forms of hierarchy between whites and black and stereotypes about black characters.

Keywords: Race relations. Racism. Advertising. Newspaper. Media.

\section{Personajes negros y blancos en los anuncios del periódicos de Paraná \\ Resumen}

Este artículo analiza algunas formas específicas de jerarquía entre blancos y negros se ve en los anuncios publicados en periódicos de Paraná (Brasil). Hemos organizado una base de datos de caracteres blancos y negros en los periódicos de Paraná publicados entre 2005 y 2007: Gazeta do Povo, O Estado do Paraná e Tribuna do Paraná, y hemos hecho una serie de muestras sobre aspectos específicos. Los anuncios de las muestras fueron sometidas a técnicas de análisis de contenido y análisis crítico del discurso. Este artículo analiza las formas de jerarquía en las muestras tomadas de los anuncios. Los resultados indican la presencia y la apreciación de determinados aspectos de los personajes negros, a la permanencia de la "blancura normativa," el blanco como estándar de la humanidad, vinculados a la expresión de una "estética aria", el mantenimiento de las viejas y nuevas formas de jerarquía entre blancos y negros y los estereotipos acerca de los personajes negros.

Palabras clave: Relaciones raciales. Racismo. Anúncios. Periódicos. Medios de comunicación.

\section{Introdução}

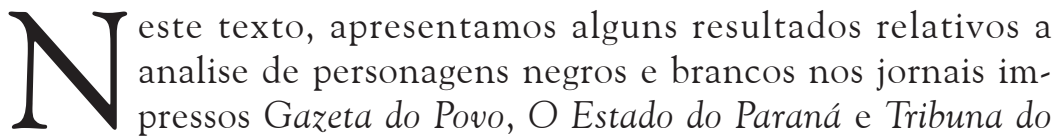


Paraná. A pergunta que orienta nossas pesquisas é: quais espaços ocupados por personagens negros nos jornais impressos? Para respondê-la, utilizamos procedimentos de análise de conteúdo, acompanhados de análise qualitativa com instrumentos de análise crítica de discurso.

Vimos trabalhando, nos últimos anos, com análise de relações raciais no plano simbólico. A proposição de nossos trabalhos é, como a proposição deste artigo, discutir algumas formas específicas de hierarquização entre brancos(as) e negros(as) que circulam em variados discursos midiáticos brasileiros. Consideramos que as desigualdades raciais são "estruturais e estruturantes" na sociedade brasileira (GOMES, 2008). Voltamos o foco de nossas pesquisas para as desigualdades raciais no plano discursivo, concebendo que: a) os discursos são produtores e reprodutores de desigualdades em diferentes eixos (de raça-etnia, gênero e sexualidade, idade, além de classe social); b) as desigualdades relativas aos bens simbólicos se relacionam de forma complexa e assíncrona com as desigualdades relativas aos bens materiais; c) na "sociedade moderna" os discursos midiáticos ocupam especial espaço de estruturação das relações de dominação (THOMPSON, 1995).

Em outro estudo (SILVA; ROSEMBERG, 2008), discutimos que diversas pesquisas vêm destacando estarem os negros ausentes ou sub-representados em discursos da mídia do Brasil. Realizando revisão de literatura sobre o discurso racial na mídia brasileira (analisando pesquisas nos campos da literatura e cinema, imprensa, televisão, literatura infanto-juvenil e livro didático), sistematizamos os resultados encontrados em quatro pontos: 1) a evidente sub-representação do negro nas diversas mídias; 2) o constante silenciamento das mídias sobre as desigualdades raciais, exercendo um duplo papel: negar os processos de discriminação racial, buscando ocultar a racialização das relações sociais, ao mesmo tempo em que propõe uma homogeneidade cultural ao brasileiro; 3) o branco é tratado como representante "natural" da espécie humana (branquidade normativa ${ }^{1}$; 4) a estereotipia na representação do homem e

\footnotetext{
${ }^{1}$ Creditamos o conceito a Rosemberg (1985), que analisou essa forma de definição do branco como norma de humanidade no discurso da literatura infato-juvenil brasileira e com a formulação nessa expressão "branquidade normativa" a Giroux (1999) em artigo sobre branquidade nos EUA.
}

Intercom - RBCC

São Paulo, v.35, n.2, p. 149-168, jul./dez. 2012 
da mulher negra, adulto ou criança é recorrentemente assinalada nas diversas mídias.

A partir dessa perspectiva crítica sobre as desigualdades raciais no Brasil e sobre o papel da mídia realizamos pesquisas sobre personagens negras (os) e brancas (os) em jornais diários de grande circulação de Curitiba, estado do Paraná (Brasil). Neste artigo sintetizamos algumas observações de análise sobre a publicidade publicada em três jornais paranaenses.

Trabalhamos na organização de um banco de dados sobre "O negro em jornais paranaenses", a partir dos jornais impressos Gazeta do Povo, O Estado do Paraná e Tribuna do Paraná publicados entre 24 de dezembro de 2005 e 31 de março de 2007. O trabalho consistiu na leitura na integra dos exemplares dos jornais, dos quais, foram separados todos os escritos de diferentes formatos (reportagens, artigos, editoriais, cartas de leitores, notas, etc.) que apresentavam personagens negros(as), descritos nos textos com vocabulário racial, acompanhados de fotos que permitiam a classificação ou personagens reconhecidos(as) como negros(as) (por exemplo, Ministro Joaquim Barbosa). As Unidades de Informação (UI) com personagens negras(os) foram coletadas, identificadas (data, dia da semana, posição no caderno), classificadas em categorias pré-definidas e arquivadas. No que se refere à publicidade, foram arquivadas todas as peças publicitárias que continham personagens humanas. Por um lado as UI arquivadas possibilitavam a análise sobre personagens negras(os) nos referidos jornais. Por outro, o arquivamento de todas as peças publicitárias com personagens humanas permite análises comparativas entre personagens de diferentes cor-etnia ou, mais preciso para nosso foco, a análise comparativa entre personagens negros(as) e brancos(as). Em projetos específicos de Iniciação Científica foram analisados determinados cadernos dos jornais - infanto-juvenis, de saúde, e de variedades dominicais nesses casos com arquivamento dos cadernos completos (alguns deles em períodos posteriores a março de 2007, ou seja, além do período de leitura completa e arquivamento de Unidades de Informação para o banco de dados), com a análise comparativa entre personagens negras(os) e brancas(os). 
A montagem do banco de dados envolveu equipes de estudantes diversas e diferentes fontes de financiamento. Inicialmente contamos com financiamento dos programas Afro-Atitude (UNESCO, Ministério da Saúde e MEC) e UNIAFRO (SECAD/MEC). Posteriormente, contamos com apoio do CNPQ e da Fundação Araucária de Apoio ao Desenvolvimento Científico e Tecnológico do Paraná. Participaram estudantes de Ciências Sociais, Psicologia, Letras, Pedagogia, História, Educação Artística, Comunicação Social, Educação Física, Enfermagem e Agronomia.

O projeto envolveu, ao longo do tempo, o acompanhamento de publicações sobre o tema "relações raciais na mídia", com constantes atualizações de pesquisas bibliográficas, e o acompanhamento de movimentação social em torno da temática, especialmente análise de documentos de reinvindicações de movimentos sociais negros e instrumentos de legislação. Neste artigo apresentamos uma síntese de resultados de análises da publicidade.

\section{Discutindo alguns resultados}

Inicialmente, apresentamos alguns resultados relativos a tratamento das peças publicitárias publicadas entre 24 de dezembro de 2005 e 24 de fevereiro de 2006 nos jornais Gazeta do Povo, O Estado do Paraná e Tribuna do Paraná. A partir do uso de procedimentos de análise de conteúdo, acompanhados de análise qualitativa com instrumentos de análise crítica de discurso. Foram observados 1759 personagens humanas compondo as peças publicitárias. Os personagens negros foram 6,8\% (120) do total (eram $24 \%$ da população do Paraná, segundo dados da PNAD de 2004) ao passo que os personagens brancos foram $87 \%$ (1530), ou seja, sub-representados os primeiros e sobre-representados os últimos. Calculamos a razão entre personagens brancas e negras, a que denominamos "taxa de branquidade", que foi de 12,75 , ou seja, para cada personagem negra nas peças publicitárias analisadas contaram-se 12,75 personagens brancas. Esse índice foi utilizado inicialmente por Rosemberg (1985) e o temos incorporado em nossos estudos por sua capacidade de explicitar as desigualdades entre brancos e negros e pelas possibilidades 
comparativas que entre indicadores e entre diferentes estudos que possibilita.

Utilizamos as variáveis proposta por Martins (2000) para análise dos personagens negros nas peças publicitárias: a) personagem agrega ou não valor à peça publicitária; b) personagem ativo ou passivo; c) hierarquia superior ou inferior de personagens negros em relação a personagens brancos; d) personagem valorizado ou não em relação ao contexto da peça publicitária. A maior parte dos personagens negros $(84,16 \%)$ agrega valor às peças publicitárias nas quais figuram. Foram $84,7 \%$ personagens negros ativos, que tinham ação própria ou influíram na cena observada, para $11,7 \%$ de personagens negros passivos. Quando junto com outros grupos de cor-etnia, a maioria $(90,6 \%)$ dos personagens negros figurou sem relações hierárquicas, $8,9 \%$ foram apresentadas em situação superior a personagem de outra cor-etnia e somente um personagem $(0,8 \%)$ figurou em posição hierárquica inferior. Tal cuidado em não apresentar o personagem negro em posição inferior à personagem de outro grupo étnico-racial pode ser interpretada como atenção à possibilidade de crítica dos movimentos negros e de pesquisadores. Mas também pode ser interpretada como relacionada à complexa ética das relações raciais vigente no Brasil (NOGUEIRA, 1985), que tende a condenar expressões mais explícitas de racismo. Finalmente, $87,4 \%$ dos personagens negros foram valorizados, em relação ao contexto das peças publicitárias. Tais avanços, sabemos, estão associados a políticas governamentais das ultimas décadas juntamente (e como consequência) com ações dos movimentos negros. Por outro lado, junto com esses resultados observamos uma tendência geral de manutenção de outras formas de hierarquia entre brancos e negros.

$\mathrm{Na}$ tabela 1 apresentamos alguns índices de atributos de personagens brancos e negros. Selecionamos somente alguns atributos, por exemplo, de idade somente os adultos, em função da extensão deste artigo. As taxas de branquidade maiores que a geral do estudo $(12,75)$ indicam maior desigualdade na categoria em específico e taxas menores o contrário. 
Tabela 1: Taxas de branquidade e atributos de personagens brancos e negros detectados em peças publicitárias publicadas em três jornais paranaenses

\begin{tabular}{lccc}
\hline \multirow{2}{*}{ Atributos } & \multicolumn{2}{c}{ Cor-etnia } & Taxa de \\
\cline { 2 - 3 } & $\begin{array}{c}\text { Branca } \\
\mathbf{N}=\mathbf{1 5 3 0}\end{array}$ & $\begin{array}{c}\text { Negra } \\
\mathbf{N = 1 2 0}\end{array}$ & \\
\hline Indivíduo & $1146(75 \%)$ & $91(76 \%)$ & 12,59 \\
\hline Feminino & $811(53 \%)$ & $44(37 \%)$ & 18,43 \\
\hline Uso de linguagem & $51(03 \%)$ & Zero & - \\
\hline Narrador & $48(03 \%)$ & Zero & - \\
\hline Atividade escolar & $337(22 \%)$ & $35(29 \%)$ & 9,62 \\
\hline Relação familiar & $200(13 \%)$ & $6(05 \%)$ & 33,33 \\
\hline $\begin{array}{l}\text { Exercício de atividade } \\
\text { profissional }\end{array}$ & $397(26 \%)$ & $54(45 \%)$ & 7,35 \\
\hline
\end{tabular}

Fontes: Tabelas de cruzamentos de cor-etnia com demais variáveis.

O índice de personagens apresentados de forma individualizada apresenta alta desigualdade, com taxa de branquidade próxima à geral $(12,59)$. No entanto, quando se observam as peças publicitárias, percebe-se que os indivíduos negros figuram quase sempre acompanhados de indivíduos brancos. É diminuta a parcela de peças publicitárias nas quais o personagem negro é personagem único, ao passo que personagens brancos únicos foram bastante comuns no universo de anúncios analisados. Os poucos anúncios com personagens negros únicos eram parte de campanhas publicitárias de estatais. Observou-se que o personagem negro figurava, via de regra, para compor cenários de "diversidade étnico-racial", mais uma vez em publicidades de estatais.

Com relação ao sexo das personagens, os índices gerais foram de predominância de personagens femininas $(53,0 \%)$ em relação às masculinas $(40,3 \%)$. No caso das personagens negras a proporção se inverteu, foram somente $42,4 \%$ personagens negras femininas para $55,4 \%$ de personagens negras masculinas. Nessa pesquisa, as mulheres brancas trocaram de lugar com os homens brancos, mas as mulheres negras foram mantidas na base.

Os resultados relativos ao uso de linguagem apontam que nas peças publicitárias analisadas os personagens que fizeram uso da 
palavra ou exerceram o papel de narrador foram raros, somente 51 no primeiro caso e 48 no segundo (ambos 3\% do total de personagens brancos). No entanto, chama a atenção o fato de serem exclusivamente os personagens brancos com esse atributo. Fazer uso da fala foi, no universo analisado, negado de forma absoluta aos personagens negros, indicando que essa pode ser uma forma de hierarquização social bastante refinada, estabelecendo os personagens brancos com maior possibilidade de se expressarem socialmente.

Outro resultado que chamou a atenção foi a desigualdade no que se refere às relações familiares. A taxa de branquidade nesse atributo $(33,33)$ quase triplicou em relação à geral $(12,75)$, indicando que a publicidade ainda não incorporou as críticas que já realizadas à telenovela (ARAÚJO, 2000), à literatura (EVARISTO, 2006), à literatura infanto-juvenil (BAZILLI, 1999), aos livros didáticos (SILVA, 2008). A publicidade parece desconhecer que os negros também constituem famílias, pois, quando analisamos as relações familiares, não encontramos nenhuma alusão ao negro no papel de casal, pai, mãe, filho ou irmão. Somente seis personagens negros com alusão à família, sempre relativo à família superior ampla (tios, avós, etc.). $\mathrm{Na}$ análise dos dados referentes a relações familiares observou-se que não só os negros são proscritos, mas também os outros grupos de cor-etnia. O branco se impôs como o modelo familiar ideal e único.

As taxas de branquidade apontam que atividades escolares e exercício de atividade profissional foram pontos de menor desigualdade (embora 9,62 e 7,35 indiquem a persistência de desigualdades altas). No que se refere ao desempenho de atividade profissional, os resultados na tabela 1 são um pouco mais favoráveis aos negros: a taxa de branquidade $(7,35)$ é menor que a média geral $(12,75)$. Observamos algumas personagens negras construídas como membros de classe média. Mas quando as peças publicitárias faziam algum tipo de associação ao exercício de profissão têm-se presente predominantemente a representação do negro vinculado ao trabalho manual e sem especialização, às profissões menos valorizadas (reitera os resultados de MARTINS, 2000). A construção simbólica estabelece o negro nos estratos sócio-ocupacionais mais baixos como fato "normal". Embora algumas 
peças coloquem os profissionais, no conjunto, em paridade, ao se observar mais atentamente nota-se que os profissionais de "base" ou "chão" da empresa são prioritariamente negros (por exemplo, os mecânicos de macacão que integram algumas peças publicitárias são, via de regra, negros).

Podemos categorizar em três grandes grupos a maioria absoluta das publicidades que trazem personagens negros: relacionadas ao meio artístico, particularmente música e cinema; relacionadas ao esporte; anúncios das empresas estatais. Na música, em sua maioria, são peças relativas a bandas, onde o negro é parte de grupo ou multidão; no cinema trazem o negro de forma valorizada, consistindo, principalmente, de personagem do cinema estadunidense; no esporte, via de regra, apresentam atletas famosos que consomem algum produto; nos anúncios de estatais observa-se o negro representante de seu grupo. Por um lado são nas peças de estatais que o negro ganha existência, onde personagens comuns têm aspectos fenotípicos valorizados ou desempenham papéis sociais não estereotipados. Por outro lado, a tendência geral é de compor um quadro de diversidade racial, ou seja, o negro existe para compor a diversidade mas a existência plena é exclusividade do branco.

$\mathrm{Na}$ estereotipização das personagens negras, o trio samba-mulata-futebol ainda se destacou. Entre as unidades com personagens negras, os anúncios de shows de samba/pagode e reggae foram parte significativa. $\mathrm{Na}$ maior parte dos casos, propagandas divulgando shows de várias bandas em um mesmo evento, entre as quais figuraram diversos personagens negros. Interpretamos que, em eventos musicais o discurso da publicidade estabelece que a presença de negros é "quase natural". Constrói-se dessa forma um discurso que determina espaços específicos de possibilidade de presença do negro. Argumentamos que essa expressão simbólica não é somente reflexo das práticas sociais. $\mathrm{O}$ discurso opera na constituição de expectativas pelos atores sociais, nesse caso estabelecendo área onde a presença do negro é aceita (reificando as ideias de mais emoção, o que geraria aptidão natural para a música), ao mesmo tempo que estabelece que outros espaços sociais, por exemplo, economia e finanças, não são espaços para negros.

Intercom - RBCC 
De forma geral, observou-se a valorização de aspectos fenotípicos de boa parte dos personagens negros analisadas, porém, foi notória a permanência de estereótipos. A criação de situações de estereotipia no plano simbólico, como na publicidade, se relaciona de forma complexa com a situação subalterna do negro na nossa sociedade brasileira, com as desigualdades no plano estrutural.

Uma estereotipia que tornou-se comum foi a do "negro assistido" (BELELI, 2005; CORREAA, 2006). Determinadas peças trabalharam com propostas de assistencialismo ou de Responsabilidade Social e em geral, foram realizadas com personagens negros desempenhando o papel de carentes. Tais imagens operam para fixar o negro como carente, necessitando de ajuda e assistencialismo para se manter. Na figura 1 observa-se a única imagem de personagens negras em contexto familiar apresentado na publicidade publicada na Gazeta do Povo.

Figura 1: Exemplo de personagens negros em relação familiar.

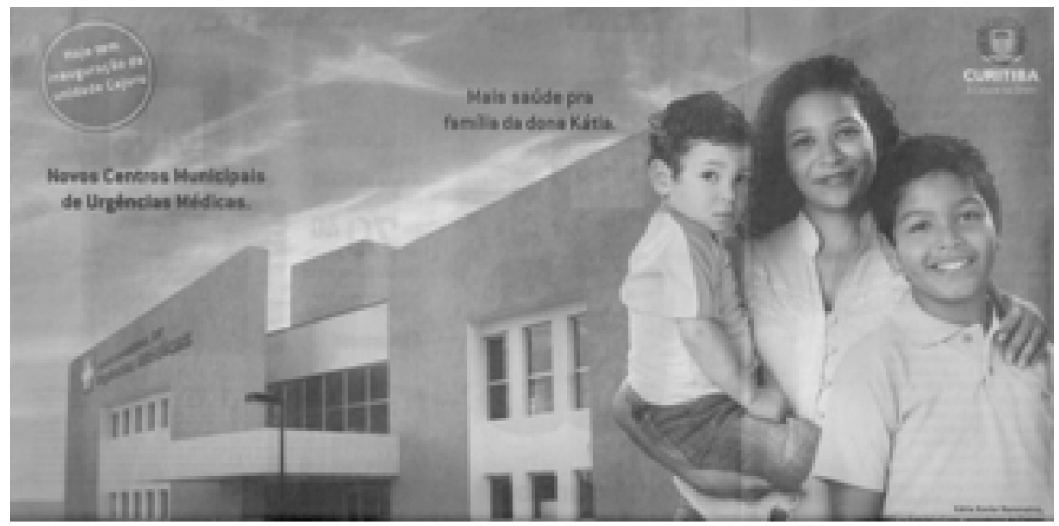

Fonte: Gazeta do Povo, Caderno Paraná, 29 mar. 2007, p. 8.

O uso desse tipo de imagem, com valorização de aspectos fenotípicos é muito comum em situações nas quais os personagens negros são objeto de intervenção de ação social, o que fixa uma imagem restritiva. A imagem retrata uma mulher com duas crianças e uma estrutura física ao fundo. Nota-se que a estrutura de família se dá pela composição de figura feminina que representa 
a mãe (ao centro) e dois garotos que fazem alusão a filhos, todos em frente a um posto de saúde público da Região de Curitiba. Um ponto peculiar da peça é a identificação da personagem central por meio do texto de chamada da peça (central, em tipo maior) e no canto inferior direito da peça publicitária o nome completo da personagem. A identificação da personagem remete à intenção da peça publicitária em aproximar, principalmente, a personagem com o estabelecimento a ser inaugurado, afinal, faz parte de sua realidade. Os aspectos fenotípicos da mãe e das crianças são valorizados, em especial pela expressão de bem estar e pelos sorrisos. Por outro lado, não se tem referência da figura do pai, que é ignorada. É um formato de representação nitidamente divergente do observado na maioria absoluta de outras peças no que se concerne à estrutura familiar, nas quais as famílias brancas, com pai, mãe e filho(s). A representação de uma mulher negra com seus dois filhos (um no colo e outro a sua frente, sob sua proteção) pode mobilizar sentidos de uma família desviante (desviante não em relação a realidade, na qual as famílias "chefiadas" por mulheres são muito comuns, mas em relação às representações de família que observamos nas publicidades e mesmo no jornais), uma possível "mãe-solteira".

Além disso, a peça traz como marca principal o arquétipo, segundo Beleli (2005) e Corrêa (2006), do "negro assistido", ou seja, o "beneficiado", aquele que agradece e reconhece o trabalho realizado pelo aparelho estatal:

Peças publicitárias majoritariamente veiculadas por instituições, em anúncios das empresas estatais, focando no assistencialismo destinado ao preto/ pobre que necessitam de apoio para conquistarem alguma ascensão social. A referida categoria atribui ao personagem negro uma existência plena, onde personagens comuns têm aspectos fenotípicos valorizados ou desempenham papéis sociais não estereotipados (CORRÊA, 2006, p.119).

Os resultados apontam que para as empresas publicitárias no Paraná uma família negra ou inter-racial não é a ideal para representar uma "família feliz". Por outro lado, pode ocupar a posição de uma família que recebe benefícios estatais, que necessita do estado para acessar os direitos básicos, como a saúde. Ainda mais, a necessidade é representada como uma família onde a figura da 
mãe se faz central, sem a figura do pai, podendo ser mobilizadora dos sentidos estigmatizantes de família sem os elementos "tradicionais" ou "naturais" que envolvem o imaginário em torno de família "estruturada".

Em outras análises que realizamos essa ausência de representação de personagens negros(as) com relações familiares expressou-se de forma muita significativa (SANTOS; SILVA, 2010). Num exemplo, analisamos as personagens negras e brancas do caderno Mais Saúde, do jornal O Estado do Paraná, com amostra de quatro meses de circulação desse caderno: março, abril, maio e junho de 2007. Enquanto observamos 23 formas de relações familiares entre personagens brancos(as), nenhuma relação familiar entre personagens negros(as) foi visualizada. Como exemplificado na figura 2, as relações familiares encontradas na amostra apontaram todas para representações de corpos saudáveis.

Figura 2: Exemplo de personagens brancos em relação familiar.

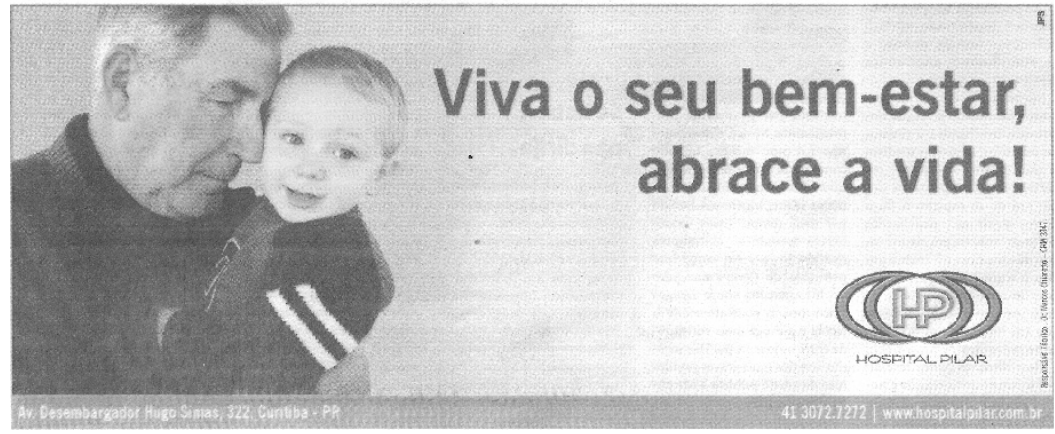

Fonte: O Estado do Paraná, Caderno Mais Saúde, 12 jun. 2007, p.8

O anúncio destaca uma relação familiar que faz alusão a família ampla inferior (neto) e a família ampla superior (avô). A disposição dos personagens na cena, exibindo o corpo do tronco para cima, assim como suas vestes de tom escuro, destaca os rostos claros de cada um. O avô está com os olhos quase fechados, com uma expressão de ternura, encostado ao rosto do neto, que com um sorriso, fita seus olhos azuis em algum ponto fora da cena. Os dizeres do anúncio "Viva o seu bem-estar, abrace a vida!" 
completam a representação de corpo saudável. Representações familiares como essa foram regra, não exceção. Interpretamos que tais formatos de publicidade atuam para estabelecer o branco como norma de humanidade e expressam a hiper-valorização dos traços fenotípicos brancos (e, acrescentamos, uma hiper-valorização da família branca), o que Araújo (2007) denomina de estética ariana.

Ao analisar as imagens das telenovelas brasileiras Araújo (2000) usou o termo estética sueca para descrever uma opção de hiper-valorização dos traços nórdicos, não somente da pele clara, mas também de cabelos e olhos os mais claros. Em comunicação posterior o autor (ARAÚJO, 2006) sugeriu o uso do conceito de estética ariana para descrever o fenômeno que observava na mídia brasileira (em especial televisão e cinema) e na mídia latino-americana. A opção pelo termo ariana representaria melhor o papel que tais discursos desempenham, de mobilizar sentidos do "racismo científico" (o racismo que se auto-denominou científico e foi muito atuante nos séculos 19 e 20), de difundir ideias de hierarquia racial que supervalorizam traços nórdicos ou "arianos" e, implicitamente, desvalorizam traços africanos e indígenas. Nos discursos racistas de países latino americanos observaram-se aspectos dessa estética ariana (SILVA, 2007).

Um último exemplo aborda como as formas de valorização de traços fenotípicos negros convive com formas, por vezes mais refinadas, de estereotipia. Analisamos amostra de dois meses (9 edições de cada) de suplementos dominicais de dois jornais impressos paranaenses: Viver Bem, do jornal Gazeta do Povo e Revista, do jornal O Estado do Paraná. Apresentamos, na figura 3, um exemplo de personagem feminina negra em contexto que faz alusão ao gênero feminino.

Trata-se da publicidade de empresa do ramo de produtos naturais de emagrecimento e beleza física. Uma jovem negra aparece, sorrindo. Sua cor de pele é destacada pelo fundo branco do anúncio e por estar nua da cintura para cima. O texto fala da celulite, que atinge a maioria das mulheres, e de como os produtos da empresa podem ajudar a resolver o problema. A jovem remete a beleza que os produtos proporcionariam. Em nenhum momento o texto faz referência a cor-etnia da jovem, o que indica que ela 
está sendo utilizada para representar o gênero feminino, ou seja, a normatividade branca é contraposta. Consideramos esse um exemplo de valorização dos traços da mulher negra - uma exceção na amostra analisada. Por outro lado, apresenta o estereótipo muito comum de mulher negra de forma erotizada, representando o corpo negro semi-nu aproximação com a natureza.

Figura 3: Exemplo de personagem negra em contexto que faz alusão ao feminino.

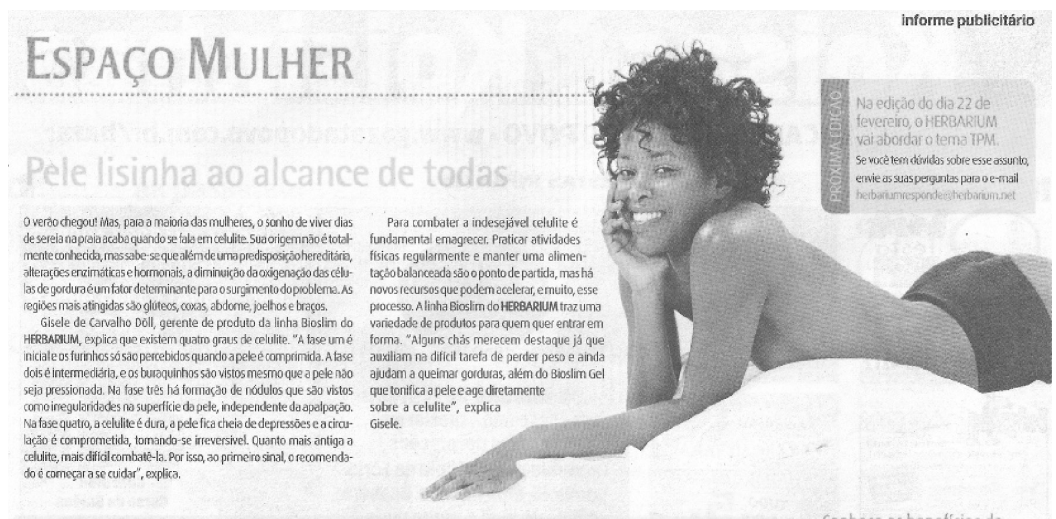

Fonte: Gazeta do Povo, Caderno Viver Bem, 18 jan. 2009, p.16.

A hiper-erotização de corpos negros é forma de estereotipia que remete aos sentidos de negros como mais próximos à natureza. Beleli (2005) observou essa característica em peças publicitárias vencedoras dos Festivais de Criação de São Paulo, entre 1975 e 2003, e por Corrêa (2006), em anúncios de telefone celular. No caso da mulher negra essa erotização remete ao estereótipo de "mulata boa" e compõe uma das formas hegemônicas de estereotipia da mulher negra em discursos literários e midiáticos (EVARISTO, 2006; SILVA; ROSEMBERG, 2008).

O discurso brasileiro construiu, no plano simbólico, um espaço de subalternidade quase total para a mulher negra, na qual as personagens tipo são a empregada doméstica (ou a escrava nas narrativas de época) e a prostituta (com suas variações de mulheres voluptuosas e hiper-sensuais). Para Evaristo (2006) a análise das personagens negras na literatura aponta o apagamen- 
to de determinados aspectos, ocultando sentidos de uma matriz africana na sociedade brasileira e do papel da mulher negra na formação da cultura nacional e, por outro lado, mobiliando sentidos de "perigosas' e "infecundas". Este apagamento das relações familiares e particularmente do papel de mãe, em diversos meios discursivos, contrasta com os papéis assumidos pela mulher negra na sociedade brasileira. As estereotipias relacionam-se com a "proibição tácita" de apresentar a mulher negra em família (na literatura infanto-juvenil ver ANÓRIA, 2003; em telenovelas brasileiras ver ARAÚJO, 2000; na literatura brasileira moderna ver DALCASTAGNÉ, 2008; em livros didáticos ver SILVA, 2008).

\section{Buscando uma síntese}

Os resultados das pesquisas apontam que embora tenha aumentado a representação do negro na publicidade, mantêm-se visível a desigualdade entre brancos e negros.

Por um lado, os resultados apontam que os personagens negros, via de regra: agregam valor às peças publicitárias; foram tendencialmente ativos; não apresentam hierarquia superior ou inferior em relação a personagens brancos em mesma peça; foram valorizados em relação ao contexto da peça publicitária em que figuram. Nessas variáveis observou-se melhora em comparação com resultados apresentados por Martins (2000) que analisou peças publicitárias publicadas na revista Veja nos anos 1990.

Por outro lado, observou-se ainda imperam formas diversas de hierarquização racial entre brancos e negros. Características expressivas que foram hegemônicas nas amostram foram a branquidade normativa, a orientação por uma estética ariana e a sub-representação de negros acompanhada de estereotipias, em especial o "negro assistido", que ganhou contornos explícitos em espaços específicos dos jornais. Ainda prevaleceu a correlação com outros estereótipos, associando personagens negros: aos esportes (principalmente futebol); à música; ao trabalho sem qualificação ou braçal; ao ócio ou malandragem. Majoritariamente, a mulher negra foi relacionada à temática sexual, no estereótipo da "mulata boa" e, em menor escala, à mammie, empregada protetora e submissa. 
Em nossa amostra a expressão exacerbada da branquidade normativa foi particularmente a relativa a relações familiares. Nas análises que realizamos sobre relações raciais em discursos midiáticos diversos fica patente uma "proibição tácita" de representar o negro em família ou a família negra, que circula da literatura brasileira para outros meios midiáticos (SILVA, 2007; SILVA; ROSEMBERG, 2007). Mesmo os casais interraciais relativamente comuns em discursos televisivos, não figuram na publicidade. Interpretamos que essa ausência de personagens negros em família relaciona-se a sentidos estigmatizantes sobre a própria condição de ser negro, que se mantêm forte o suficiente no imaginário a ponto de orientarem diversas áreas de produção cultural e midiática.

Nesse caso em específico, a representação de famílias, a normatividade branca impera e em geral se alia à estética ariana. É como se as imagens de reciprocidade, ternura, fraternidade, harmonia da família (sentidos mobilizados e supostos para família, quase sempre implicitamente) somente pudessem ser representadas por traços nórdicos.

Uma defesa bastante comum, em especial no que se refere à representação do negro em condição social de desvantagem, é que seria uma expressão da realidade, uma transposição da realidade que é desigual para os discursos midiáticos. No caso específico das famílias, como nas representações de mulheres negras, apontamos que os discursos ativamente produzem desigualdade de raça e gênero. Ao passo que a realidade é múltipla e contraditória, apresenta traços de heterogeneidade e muitas vezes rupturas, os discursos midiáticos apresentam uma homogeneidade que é altamente expressiva. Os espaços sociais tão restritos criam uma série de expectativas sociais e de pautas de conduta que reconhecemos, operando socialmente para criar e manter subalternidades.

Em relação à sub-representação de personagens negros, um aspecto significativo é a concentração nas peças de publicidade oficias e de estatais. Caso isoladas as peças publicitárias somente de empresas privadas os personagens negros praticamente desaparecem e em suas raras entradas as estereotipias aumentam. Ou seja, toda a mobilização de ativistas e pesquisadores, desde pelo menos a segunda metade dos anos 1980, fazendo críticas sobre 
as ausências e estereotipias em relação aos negros, atuando para a aprovação de mecanismos de legislação, promovendo estudos, seminários, publicações, parece ter um alcance restrito e circunscrito à publicidade com recursos públicos. O papel indutor do estado, em relação à publicidade oficial parece ter sido o responsável quase exclusivo pelas mudanças que se observa ao longo das últimas décadas.

Nas legislações, por exemplo, iniciou-se um processo nos anos 1990 de aprovação de leis orgânicas nos municípios de Goiânia, Vitória, Belo Horizonte, Aracaju e Rio de Janeiro, de artigos nas constituições estaduais do Rio de Janeiro, Bahia, Mato Grosso e Pará, de mudanças na Constituição Federal (Lei n. 9559 de 13 de maio de 1997) chegando às proposições do Estatuto da Igualdade Racial (uma discussão mais aprofundada consta em SILVA; SANTOS; ROCHA, 2010), com estabelecimento de normas sobre a representação na mídia da diversidade étnico-racial do país, via de regra passando por determinações de que a publicidade dos diferentes entes da federação passassem a cumprir determinados parâmetros. O Estatuto da Igualdade Racial na primeira versão apresentada em 2000 (Projeto de Lei 3.198/00) previa percentual mínimo de $40 \%$ de afrodescendentes na publicidade. No substitutivo apresentado em 2006 pelo próprio autor do projeto (Senador Paulo Paim) previa mínimo de $20 \%$ para toda a publicidade veiculada em televisão e cinema e toda publicidade governamental, sendo pelo menos metade de mulheres afro-brasileiras. No texto aprovado, Lei 12.288 de 20 de julho de 2010, mantiveram-se alguns artigos sobre os meios de comunicação, mas as cotas percentuais foram retiradas do texto da lei:

\section{DOS MEIOS DE COMUNICAÇÃO}

Art. 43. A produção veiculada pelos órgãos de comunicação valorizará a herança cultural e a participação da população negra na história do País. Art. 44. Na produção de filmes e programas destinados à veiculação pelas emissoras de televisão e em salas cinematográficas, deverá ser adotada a prática de conferir oportunidades de emprego para atores, figurantes e técnicos negros, sendo vedada toda e qualquer discriminação de natureza política, ideológica, étnica ou artística.

Parágrafo único. A exigência disposta no caput não se aplica aos filmes e programas que abordem especificidades de grupos étnicos determinados. 
Art. 45. Aplica-se à produção de peças publicitárias destinadas à veiculação pelas emissoras de televisão e em salas cinematográficas o disposto no art. 44.

Art. 46. Os órgãos e entidades da administração pública federal direta, autárquica ou fundacional, as empresas públicas e as sociedades de economia mista federais deverão incluir cláusulas de participação de artistas negros nos contratos de realização de filmes, programas ou quaisquer outras peças de caráter publicitário.

$\S 1$ o Os órgãos e entidades de que trata este artigo incluirão, nas especificações para contratação de serviços de consultoria, conceituação, produção e realização de filmes, programas ou peças publicitárias, a obrigatoriedade da prática de iguais oportunidades de emprego para as pessoas relacionadas com o projeto ou serviço contratado. (BRASIL, 2010).

Por um lado a Lei apresenta redação um tanto genérica e o não estabelecimento de percentuais (mais a abertura para representação de especificidades de grupos étnicos determinados) atuam de forma a que o papel indutor do estado perca em força e possa ser escamoteado mais facilmente. Por outro a Lei cita especificamente a população negra em dois artigos, pontos que podem ser utilizados como balizadores de pressão social por movimentos sociais, inclusive com possíveis demandas ao judiciário.

Para a pesquisa abre uma questão relevante que é a comparação entre os momentos anteriores e posteriores à aprovação do Estatuto da Igualdade Racial e análise de possíveis impactos na comunicação em geral e na publicidade em particular. Novas análises podem ser, portanto, significativas para analisar se a mudança da legislação trás modificações em relação aos resultados que apresentamos neste artigo.

\section{Referências}

ARAÚJO, Joel Zito. A negação do Brasil: o negro na telenovela brasileira. São Paulo: Editora SENAC São Paulo, 2000.

. Negros e brancos na mídia. Trabalho apresentado no IV Congresso

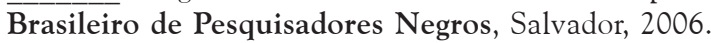

BAZILLI, Chirley. Discriminação contra personagens negros na literatura infanto-juvenil brasileira contemporânea. Dissertação (Mestrado em Psicologia Social), Pontifícia Universidade Católica de São Paulo, 1999. 
BELELI, Iara. Marcas da diferença na propaganda brasileira. Tese (doutorado em Ciências Sociais). Unicamp, 2005. $157 f$.

BRASIL. Estatuto da Igualdade Racial. Lei Federal 12.288 de 20 de julho de 2010.

CORRÊA, Laura Guimarães. De corpo presente: o negro na publicidade. Dissertação (Mestrado em Comunicação Social), Universidade Federal de Minas Gerais, 2006.

DALCASTANGÉ, Regina. Entre silêncios e estereótipos: relações raciais na literatura brasileira contemporânea. Estudos de literatura brasileira contemporânea. Brasília, n. 31, p. 87-110, jan./jun. 2008.

EVARISTO, Conceição. Gênero e etnia: uma escre(vivência) de dupla face. Trabalho apresentado no IV Congresso Brasileiro de Pesquisadores Negros. Salvador, 13 a 16 de setembro de 2006.

GIROUX, Henry, A. Por uma pedagogia e política da branquidade. Cadernos de pesquisa. São Paulo, n. 107, p. 97-132, jul. 1999.

GOMES, Nilma L. Relações raciais e políticas educacionais. Seminário realizado no Programa de Pós-Graduação em Educação da Universidade Federal do Paraná. Curitiba, 2008.

MARTINS, M. C. S. A personagem afro-descendente no espelho publicitário de imagem fixa. Tese (doutorado em Comunicação e Semiótica). Pontifícia Universidade Católica de São Paulo, 2000. 189p.

NOGUEIRA, Oracy. Tanto preto quanto branco: estudos de relações raciais. São Paulo: T. A. Queiroz, 1985.

ROSEMBERG, Fulvia. Literatura Infantil e Ideologia. São Paulo: Global, 1985.

SANTOS, Wellington O.; SILVA, Paulo V. B. Racismo discursivo e a mulher negra: análise a partir dos personagens presentes na publicidade e nos cadernos de saúde de jornais impressos. Revista Theomai (Online), Buenos Aires: Red de Estudios sobre Sociedad, Naturaleza y Desarrollo, v. 01, p. 161-169, 2010. Disponível em: http://revista-theomai.unq.edu.ar/. Acesso em:

SILVA, Paulo V. B Notas sobre os escritos do projeto "Racismo e discurso na América Latina”. In: VI Congresso Latinoamericano de Estudios del Discurso. VI Congresso Latinoamericano de Estudios del Discurso. Bogotá: Asociacion Latinoamericana de Estudios del Discurso, 2007. v.1. p.1-15

Intercom - RBCC

São Paulo, v.35, n.2, p. I49-I68, jul./dez. 2012 
SILVA, Paulo V. B. Relações raciais em livros didáticos de língua portuguesa. Belo Horizonte: Autêntica, 2008.

SILVA, Paulo V. B. Projeto "Racismo e discurso na América Latina": notas sobre personagens negras e brancas no discurso midiático brasileiro. In: III Simpósio Internacional sobre Análise do Discurso. Belo Horizonte, Núcleo de Análise do Discurso (NAD) e o Programa de Pós-Graduação da Faculdade de Letras da Universidade Federal de Minas Gerais, 1ํa 4 de abril de 2008b.

SILVA, Paulo V. B.; ROSEMBERG, Fúlvia. Brasil: lugares de negros e brancos na mídia In: VAN DIJK, Teun (Org.). Racismo e Discurso na América Latina. São Paulo: Contexto, 2008.

SILVA, Paulo V. B., SANTOS, Wellington O.; ROCHA, Neli G. Racismo discursivo, legislação e proposições para a televisão pública brasileira In: ARAÚJO, Joel Z. (org.) O negro na TV pública. Brasília: Fundação Cultural Palmares, 2010. v.1, p. 81-112.

THOMPSON, John B. Ideologia e cultura moderna: teoria social crítica na era dos meios de comunicação de massa. Petrópolis: Vozes, 1995. 